\title{
Sixty Nine
}

National Cancer Institute

\section{Source}

National Cancer Institute. Sixty Nine. NCI Thesaurus. Code C105793.

A natural number greater than sixty-eight and less than seventy and the quantity that it denotes. 